\title{
INCIDENCE OF ANTIBODIES IN CEREBROSPINAL FLUID OF PATIENTS WITH MULTIPLE SCLEROSIS TREATED WITH INTERFERON BETA
}

\author{
Andres M. Villa', Cristina Videla ${ }^{2}$, Orlando Garcea', Guadalupe Carballal ${ }^{2}$
}

Interferon beta (IFN $\beta$ ) is used in the treatment of multiple sclerosis (MS) because it can reduce relapse rate and lesion formation on MRI and can slow progression of the disease $\mathrm{e}^{1-3}$. As has been observed with other protein-based drugs, some patients develop neutralizing antibodies (NAbs) during chronic administration of IFN $\beta$. The proportion of patients developing NAbs ranges from $25 \%$ for the 3-times-weekly subcutaneous IFN $\beta$-la regimen to $2 \%$ for the once-weekly intramuscular IFN $\beta$-la regimen ${ }^{4}$. Published data from large, randomized clinical trials demonstrate that efficacy is reduced in patients who are NAbpositive $(\mathrm{NAb}+)$ compared with those who are NAb-negative $(\mathrm{NAb}-)^{3,5}$. Neutralizing antibodies can potentially cross the blood-brain barrier (BBB) in IFN $\beta$-treated patients with relapsing-remitting multiple sclerosis (RRMS) and impair endogenous IFN $\beta$ function within the central nervous system (CNS). This theory is supported by the results of a study by Shapiro et al. ${ }^{6}$, which demonstrated that in human astrocytes in culture, high serum titers of NAbs (1865-19,320 tenfold reduction units [TRU]) inhibit toll-like receptor-3 ligand and endogenous IFN $\beta$-mediated production of CXCL10 and IL-6.

\section{CASES}

We selected NAb+ patients treated with IFN $\beta$ over a period of 6-24 months were screened for the presence of NAbs and binding antibodies (BAbs) against IFN $\beta$ in cerebrospinal flu- id (CSF). Titers of NAbs were determined using the cytopathic effect assay. Patients were considered NAb- if their NAbs titer was $<20$ TRU. Patients who were NAb+ were selected for concurrent CSF and sera sampling to look for the presence of NAbs and BAbs. The samples were stored at $-20^{\circ} \mathrm{C}$ prior to assay. Enzyme-linked immunosorbent assay (ELISA) was performed to determine BAb titer in CSF and serum samples. Patients were considered $\mathrm{BAb}-$ if their $\mathrm{BAb}$ titer was $<30$ Bühlmann titer units (BTU; [Bühlmann Laboratories AG, Switzerland]).

Three patients with moderately high serum NAb and BAb titers were selected for further screening for BAbs and NAbs in the CSF: 2 patients treated with IFN $\beta-16$ (titers of 570 TRU and $>500$ BTU, and 26 TRU and 35 BTU, respectively) and 1 patient treated with subcutaneous IFN $\beta$-1a (titer of 489 TRU and $>500$ BTU). None of these patients were positive for BAbs in the CSF (Table).

\section{DISCUSSION}

This case study shows that patients with positive titers of NAbs and BAbs in serum did not have detectable NAbs and BAbs in the CSF. However, the absence of these antibodies in the CSF does not eliminate the possibility that antibodies can cross the BBB locally in the area of inflammation yet not reach detectable levels in the CSF.

ACKNOWLEDGEMENT - The authors thank Matthew Hasson, Scientific Connexions, Newtown, PA, USA for editorial assistance in preparing this manuscript.

Table. Assessment of BAbs in CSF of patients with high serum NAb titers.

\begin{tabular}{cccc}
\hline Patient ID & NAbs (serum, TRU) & BAbs (serum, BTU) & BAbs (CSF, BTU) \\
\hline 1 & 26 & 35 & ND \\
2 & 570 & $>500$ & ND \\
3 & 489 & $>500$ & ND \\
\hline
\end{tabular}

BAb, binding antibody; CSF, cerebrospinal fluid; NAb, neutralizing antibody; TRU, tenfold reduction unit; BTU, Bühlmann titer unit; ND, not detectable.

\section{INCIDÊNCIA DE ANTICORPOS NO LÍQUIDO CEFALORRAQUIDIANO EM PACIENTE COM ESCLEROSE MÚLTIPLA TRATADO COM INTERFERON BETA}

'División Neurología, Hospital General de Agudos “José María Ramos Mejía," School of Medicine, Buenos Aires University, Buenos Aires, Argentina; ${ }^{2}$ Laboratorio de Virología Clínica, CEMIC, Buenos Aires, Argentina. This research was supported by Biogen Idec, Inc., Cambridge, MA, USA.

Received 27 April 2009. Accepted 25 July 2009.

Dr. Andres M. Villa - División Neurología / Hospital General de Agudos "José María Ramos Mejía” / School of Medicine / Buenos Aires University Urquiza 609 (1221) - Buenos Aires, Argentina. E-mail: amvilla@fibertel.com.ar 


\section{REFERENCES}

1. Jacobs LD, Cookfair DL, Rudick RA, et al. Intramuscular interferon beta-1a for disease progression in relapsing multiple sclerosis. Ann Neurol 1996;39:285-294.

2. Prevention of Relapses and Disability by Interferon Beta-1a Subcutaneously in Multiple Sclerosis (PRISMS) Study Group. Randomized, double-blind, placebo-controlled study of interferon-beta 1a in relapsingremitting multiple sclerosis: clinical results. Lancet 1998;352:1498-1504.

3. The IFNB Multiple Sclerosis Study Group and the University of British Columbia MS / MRI Analysis Group. Neutralizing antibodies during treatment of multiple sclerosis with interferon beta- $1 \mathrm{~b}$ : experience during the first three years. Neurology 1996;47:889-894.
4. Panitch H, Goodin DS, Francis G, et al. Randomized, comparative study of interferon $\beta$-1a treatment regimens in MS: the EVIDENCE trial. Neurology 2002;59:1496-1506.

5. PRISMS (Prevention of Relapses and Disability by Interferon Beta-1a Subcutaneously in Multiple Sclerosis) Study Group and the University of British Columbia MS/MRI Analysis Group. PRISMS-4: longterm efficacy of interferon-b-1a in relapsing MS. Neurology 2001;56: 1628-1636.

6. Shapiro AM, Jack CS, Lapierre Y, et al. Potential for interferon beta-induced serum antibodies in multiple sclerosis to inhibit endogenous interferon-regulated chemokine/cytokine responses within the central nervous system. Arch Neurol 2006;63:1296-1299. 